\title{
Acute mitral regurgitation in pregnancy due to ruptured chordae tendineae
}

\author{
P. K. Caves and M. Paneth \\ From the Brompton Hospital, London
}

\begin{abstract}
Rupture of chordae tendineae resulting in acute mitral regurgitation has previously been described following rheumatic fever, subacute bacterial endocarditis, blunt chest trauma, and in Marfan's syndrome. Chordae may rupture spontaneously in older patients, producing a characteristic clinical syndrome, but such 'idiopathic' rupture is exceptional before the age of 50. This paper reports the occurrence of acute mitral regurgitation due to spontaneous rupture of the chordae tendineae in a previously healthy 19-year-old girl during her second pregnancy. A similar case - has not previously been described. Since the clinical and haemodynamic findings were very similar to those seen in older patients, the correct diagnosis was made preoperatively.

At operation, rupture of the chordae to the posterior leaflet was found and the valve was replaced by a frame-mounted aortic homograft. Two months later this became detached from the annulus posteriorly and was successfully resutured at a second operation.
\end{abstract}

- In Britain rheumatic heart disease now accounts for approximately 75 per cent of cardiac lesions in pregnancy: of these, 75 per cent have dominant mitral stenosis and a further 15 per cent have combined aortic and mitral valve disease (Mendelson, 1960; Wood, 1962). Idiopathic mitral regurgitation during

$r$ pregnancy is rare but it may also occur after rheumatic or bacterial damage to the valve leaflets. Late rupture of the chordae producing mitral regurgitation has also been described after theumatic fever or subacute bacterial endocarditis (Menges, Ankeney and Hellerstein, 1964; Sanders et al., 1965; Selzer et al., 1967). Rarely, chordae may rupture after blunt chest trauma (McLaughlin et al., 1964), - or in Marfan's syndrome (Simpson, Nora, and McNamara, 1969).

In recent years idiopathic rupture of the chordae tendineae has been increasingly recognized at operation as a cause of severe mitral regurgitation (January, Fisher, and Ehrenhaft, 1962; Ellis, Frye, and McGoon, 1966; Sanders et al., 1967; Gerbode et al., 1968). Such idiopathic rupture often produces a characteristic syndrome which permits its clinical recognition.

\section{Case report}

The patient was admitted in March 1968 at 35 weeks' gestation. Eighteen months earlier she had had a normal delivery at term of her first child.
At that time her heart was stated to be normal and there had been no deterioration in exercise tolerance throughout the pregnancy, or during the puerperium.

In the sixth week of her second pregnancy she developed streaky haemoptysis lasting one week. There were no features to suggest rheumatic fever or subacute bacterial endocarditis at that time, though no special investigations were performed. After this she developed exertional dyspnoea and anorexia, losing approximately one stone in weight. In February 1968, when 30 weeks' pregnant, she was admitted to another hospital with a tender, swollen left leg. Deep venous thrombosis and a pansystolic praecordial murmur were noted. Thromboembolic pulmonary hypertension with tricuspid regurgitation was suspected. Anticoagulants were started, and after five weeks she was transferred to the Brompton Hospital for further investigation.

On admission her exercise tolerance was grade 3 (American Heart Association classification). There were no stigmata of Marfan's syndrome, or of bacterial endocarditis. Her pulse was in sinus rhythm at 120 a minute, with a blood pressure of 130/65 mmHg. The jugular venous pressure was raised $4 \mathrm{~cm}$, with a dominant ' $a$ ' wave. The cardiac impulse was left ventricular in type, with a left parasternal lift. There was a palpable systolic thrill at the apex and a diamond-shaped systolic murmur was heard, maximal in the praecordial area but conducted over the whole chest and back. There was a third heart sound, and the pulmonary component of the second sound was accentuated. Her right leg was slightly discoloured due to varicose veins but was not tender or swollen. The 

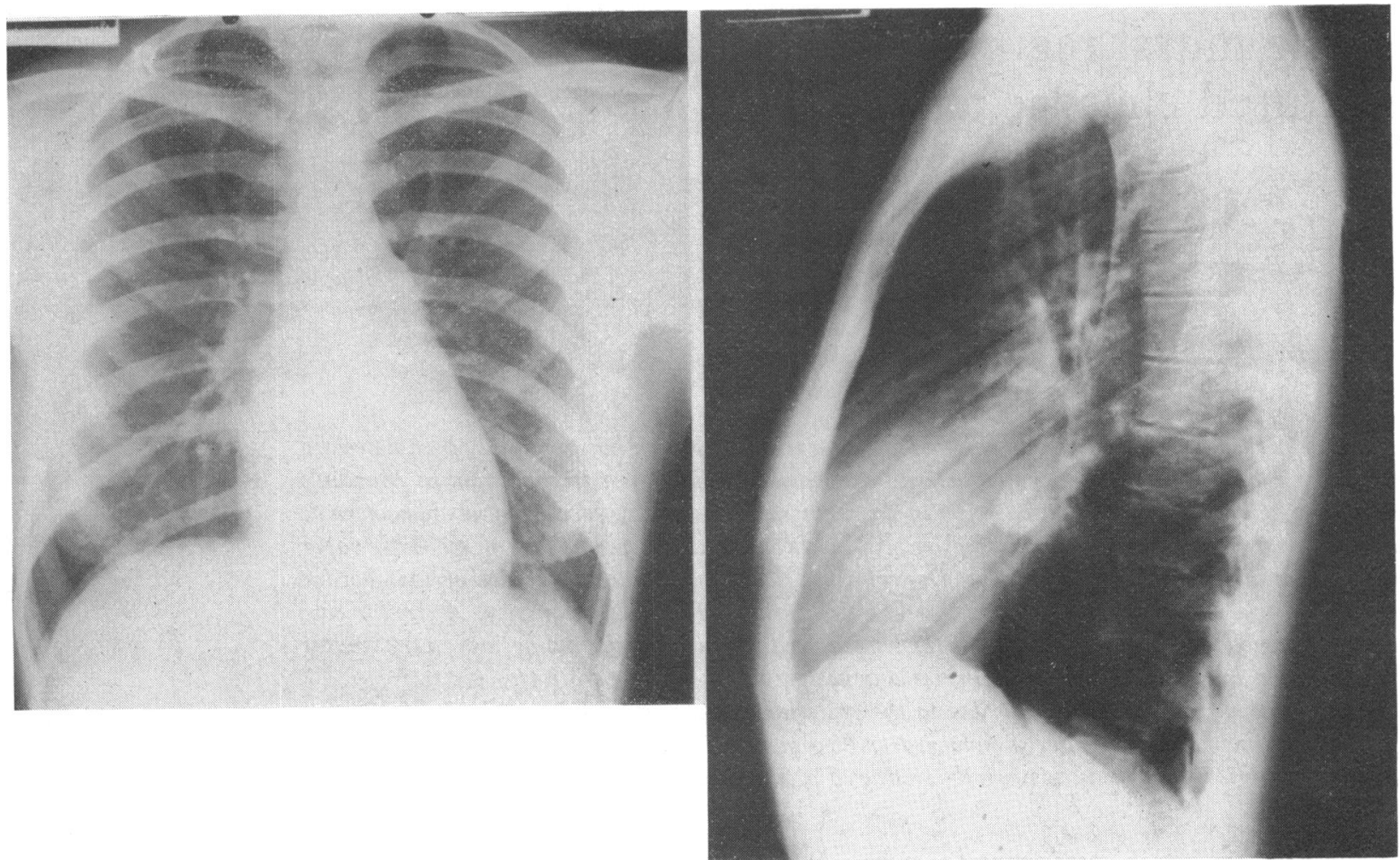

$1 a$

16

FIG. I Posteroanterior and lateral chest $\mathrm{x}$-ray showing small heart and only mild enlargement of the left atrium with considerable upper lobe venous dilatation.

uterus was enlarged corresponding to a 35 -week pregnancy and the fetal heart sounds were normal.

Investigations Standard I2-lead electrocardiogram confirmed sinus rhythm, with a normal axis $(+750)$ and left ventricular hypertrophy. The chest $x$-ray showed mild cardiac enlargement, mainly involving the right atrium but with mild left atrial enlargement as well. There was upper lobe vein distension and no intracardiac calcification was seen (Fig. I). Right heart catheterization revealed a right atrial 'a' wave of $15 \mathrm{mmHg}$ and a pulmonary artery pressure of $58 / 30 \mathrm{mmHg}$, with a mean of 45 . The pulmonary artery wedge pressure had a mean value of 33 , with a high, late ' $v$ '-wave of $50 \mathrm{mmHg}$ (Fig. 2). The cardiac index was 3.3 and the pulmonary arteriolar resistance was $3.6 \mathrm{u} / \mathrm{m}^{2}$.

Progress She was treated with digoxin 0.25 $\mathrm{mg}$ b.d. and frusemide, and was delivered by forceps of a normal male child on 3 May 1968. After this she continued to be breathless on exertion and easily fatigued. Cardiac catheterization was repeated in October 1968, at which time a left ventricular angiogram was obtained. The pressure recordings were very similar to those in March and the angiogram confirmed severe mitral regurgitation with a small left atrium.

Operation (24 October 1968) The heart was exposed through a right anterolateral thoracotomy. The right side of the heart appeared normal but the left atrium and pulmonary veins were under considerable tension, with a powerful systolic thrill. With total cardiopulmonary bypass, the left atrium was entered directly. The mitral valve was grossly incompetent due to rupture of all the chordae from the postero-medial papillary muscle to the medial half of the posterior leaflet. The valve leaflets were normal in size and the annulus was not dilated but was noted to be rather soft. Repair of the valve was not attempted and the valve was excised and replaced with a formalin-preserved aortic homograft mounted on a metal stent and sutured into the mitral annulus with interrupted mattress sutures.

After operation she noted improvement for two months but then suddenly deteriorated again. She was readmitted as an emergency in February I969, in failure with signs of gross mitral regurgitation. Cardiac catheterization and left ventricular angiography showed regurgitation around the posterior part of the prosthesis. 


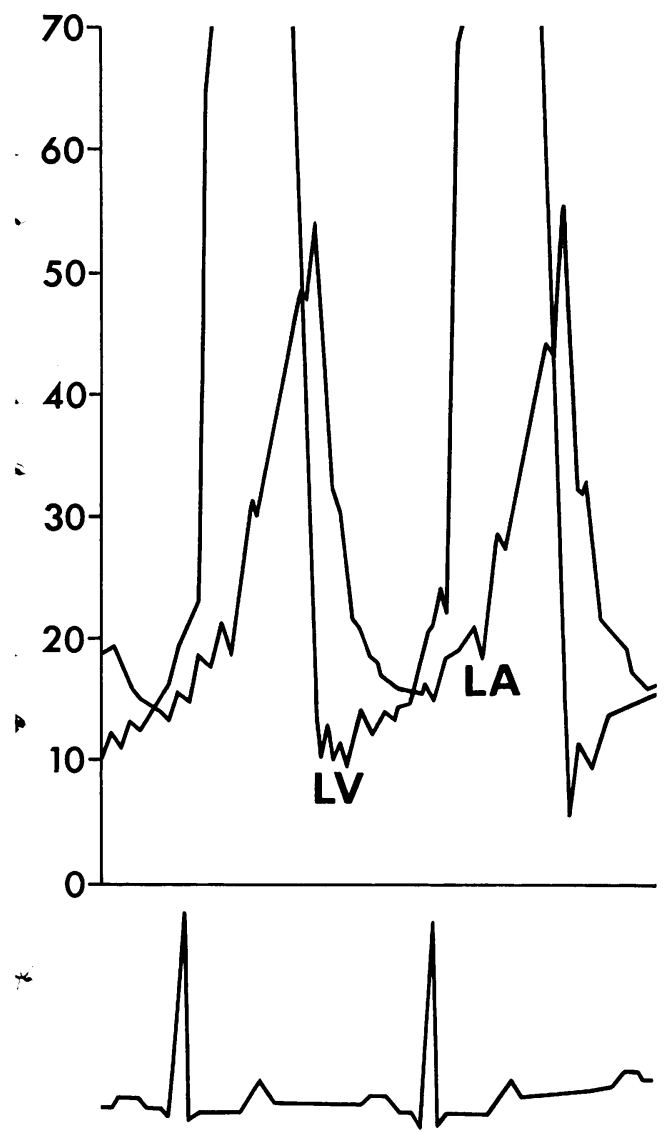

FIG. 2 Left ventricular ( $L V)$ and pulmonary artery wedge pressure $(L A)$ traces showing

'high late ' $V$ ' wave in the left atrium

(pressures measured in $\mathrm{mmHg}$ ).

At reoperation the homograft was in good condition, but the sewing ring had become detached from the mitral annulus posteriorly. It was reattached with a series of interrupted stitches, restoring complete competence.

- After the second operation she made excellent progress and 2 years later is well, with only slight dyspnoea on severe exertion.

\section{Discussion}

Acquired mitral valve disease in young adults is usually assumed to be rheumatic in origin ' even in the absence of a definite history of such an infection. It is not uncommon for mitral disease to declare itself for the first time during pregnancy, when a considerable increase in blood volume and cardiac output takes place. In this case there was no evidence of heart disease during her first pregnancy or - in the succeeding 12 months. Symptoms began quite suddenly in the middle of the first trimester of the second pregnancy, with dyspnoea preceded by a short episode of haemoptysis. At that time there were no features of rheumatic fever or of bacterial endocarditis and there was no history of previous chest trauma. Her breathlessness and fatigue increased but a pansystolic praecordial murmur was only noted for the first time 6 months later when she was admitted with a deep venous thrombosis of the left leg. The diagnosis of mitral regurgitation due to ruptured chordae was made on the basis of the characteristic clinical findings.

I) The sudden onset and rapid progression of dyspnoea and fatigue in a previously healthy patient.

2) The finding of severe mitral regurgitation, producing a systolic thrill, a widely radiating pansystolic murmur, an accentuated pulmonary component of the second heart sound and a third heart sound.

3) Sinus rhythm.

4) Minimal enlargement of the left atrium.

In a recent study of subvalvar mitral regurgitation we have found this picture invariably to be due to rupture or dysfunction of the subvalvar mechanism (P. K. Caves et al., unpublished data). The diagnosis was supported by the findings of a high, late ' $v$ ' wave in the pulmonary artery wedge trace and by the left ventricular cineangiogram. It was confirmed at the first operation, when rupture of the posterior leaflet chordae was found.

In our experience it is exceptional for patients to rupture mitral chordae before the age of 50 years without an obvious predisposing aetiological factor. In younger patients previous bacterial endocarditis or rheumatic infection have been the commonest findings (Menges et al., 1964; Roberts, Braunwald, and Morrow, 1966). Raftery, Oakley, and Goodwin (1966) mention a case of bacterial endocarditis occurring in pregnancy which resulted in ruptured mitral chordae. In our case there was no evidence of any aetiological factor other than the pregnancy, and it is difficult to avoid the conclusion that the rupture of the chordae was in some way related to this event. It was noted that the mitral annulus and the leaflets felt soft, in contrast with the findings in older patients. This softening may have been related to the hormonal changes of pregnancy and may thus have been a factor both in the rupture of the posterior leaflet chordae, and later in the detachment of the prosthesis posteriorly.

Spontaneous rupture most commonly involves the chordae controlling the posterior 
leaflet, as occurred in this case. Why this should be so is not clear.

Various techniques of repair have been described in patients with ruptured chordae and normal mitral valve leaflets (McGoon, 1960; Morris, Penner, and Brandt, 1964; Kay, Tsuji, and Redington, 1965; Ellis et al., 1966; Merendino and Hessel, 1967). In this case a repair was not attempted because it was not thought to be feasible or safe and the valve was therefore excised and replaced with a frame mounted aortic homograft preserved in formalin.

The figures were prepared in the Medical Art Department and the Photographic Department, The Royal Marsden Hospital.

\section{References}

Ellis, F. H., Frye, R. L., and McGoon, D. C. (1966). Results of reconstructive operations for mitral insufficiency due to ruptured chordae tendineae. Surgery, 59, 165.

Gerbode, F., Hill, J. D., Kelly, J. J., Selzer, A., and Kerth, W. J. (1968). Surgical correction of mitral insufficiency due to ruptured chordae tendineae. Circulation, 37-38, Suppl. 2, I19.

January, L. E., Fisher, J. M., and Ehrenhaft, J. L. (I962). Mitral insufficiency resulting from rupture of normal chordae tendineae. Circulation, 26, 1329.

Kay, J. H., Tsuji, H. K., and Redington, J. V. (1965). The surgical treatment of mitral insufficiency associated with torn chordae tendineae. Annals of Thoracic Surgery, 1, 269.

McGoon, D. C. (1960). Repair of mitral insufficiency due to ruptured chordae tendineae. Fournal of Thoracic and Cardiovascular Surgery, 39, 357.

McLaughlin, J. S., Adams Cowley, R., Smith, G., and Matheson, N. A. (1964). Mitral valve disease from blunt trauma. Fournal of Thoracic and Cardiovascular Surgery, 48, 261.
Mendelson, C. L. (1960). Cardiac Disease in Pregnancy; Medical Care, Cardiovascular Surgery, and Obstetric Management as Related to Maternal and Foetal Welfare. Davis, Philadelphia.

Menges, H., Jr., Ankeney, J. L., and Hellerstein, H. K. (1964). The clinical diagnosis and surgical management of ruptured mitral chordae tendineae. Circulation, 30, 8.

Merendino, K. A., and Hessel, E. A. (1967). The 'murmur on top of the head' in acquired mitral insufficiency. Fournal of the American Medical Association, 199, 892.

Morris, J. D., Penner, D. A., and Brandt, R. L. (1964). Surgical correction of ruptured chordae tendineae. Fournal of Thoracic and Cardiovascular Surgery, 48, 772.

Raftery, E. B., Oakley, C. M., and Goodwin, J. F. (1966). Acute sub-valvar mitral incompetence. Lancet, 2, 360.

Roberts, W. C., Braunwald, E., and Morrow, A. G. (1966). Acute severe mitral regurgitation secondary to ruptured chordae tendineae. Circulation, 33, 58.

Sanders, C. A., Austen, W. G., Harthorne, J. W., Dinsmore, R. F., and Scannell, J. G. (1967). Diagnosis and surgical treatment of mitral regurgitation secondary to ruptured chordae tendineae. New England fournal of Medicine, 276, 943.

Sanders, C. A., Scannell, J. G., Harthorne, J. W., and Austen, W. G. (1965). Severe mitral regurgitation secondary to ruptured chordae tendineae. Circulation, 31, 506.

Selzer, A., Kelly, J. J., Vannitamby, M., Walker, P., Gerbode, F., and Kerth, W. J. (I967). The syndrome of mitral insufficiency due to isolated rupture of the chordae tendineae. American fournal of Medicine, 43, 822.

Simpson, J. W., Nora, J. J., and McNamara, D. G. (1969). Marfan's syndrome and mitral valve disease: acute surgical emergencies. American Heart Fournal, 77, 96.

Wood, P. (1962). Diseases of the Heart and Circulation, and ed. Eyre and Spottiswoode, London.

Requests for reprints to $M$. Paneth, Esq., F.R.C.S., Brompton Hospital, London S.W.3. 